\title{
O USO DO WEBCEF PARA AVALIAÇÃO DA PRODUÇÃO ORAL EM LÍNGUA INGLESA NA FORMAÇÃO INICIAL DE PROFESSORES
}

\author{
Ana Cristina Biondo Salomão ${ }^{1}$
}

\begin{abstract}
Resumo
Estudos mostram que muitos professores de inglês no Brasil ministram aulas usando sua língua materna por falta de confiança em sua proficiência oral na língua estrangeira. Neste artigo, discutimos a visão de alunos de graduação em Letras sobre o uso do WebCEF, uma plataforma on-line voltada para a avaliação da produção oral em língua estrangeira. Ela oferece a possibilidade de se fazer o upload de um vídeo gravado com a própria produção oral do aprendiz para que ele se autoavalie ou que seja avaliado por outra pessoa por meio de critérios baseados no Quadro Europeu Comum de Referência para as Línguas. Neste artigo, apresentamos os resultados de um estudo de natureza qualitativa, no qual analisamos a perspectiva de alunos que cursaram disciplinas nas quais essa ferramenta foi usada. Por meio da análise de questionários semiestruturados, buscamos compreender suas expectativas, reações e opiniões sobre as possibilidades de auxílio providas pelo WebCEF. Acreditamos que ferramentas como essa possibilitam ao professor em formação construir sua autonomia e estratégias metacognitivas que possam auxiliá-lo no desenvolvimento de sua produção oral em língua estrangeira. Nosso estudo mostra, no entanto, que ainda é preciso trabalhar o conceito de avaliação, autoavaliação e avaliação por pares, especialmente na formação de professores, para que possamos usá-los como fonte de (re)conhecimento e (re)dimensionamento da produção oral em língua estrangeira dos alunos-professores.
\end{abstract}

Palavras-chave: ensino e aprendizagem de línguas; proficiência oral; WebCEF.

\section{THE USE OF WEBCEF FOR ORAL PRODUCTION ASSESSMENT IN ENGLISH LANGUAGE IN INITIAL TEACHER EDUCATION}

\begin{abstract}
Studies show that several English teachers in Brazil end up teaching in their mother tongue due to lack of confidence in their oral proficiency in the foreign language. In this article, we discuss the views of undergraduate students majoring in English Language and Literature about the use of WebCEF, an online platform for assessing oral production in a foreign language. It offers the possibility of uploading a recorded video and performing self or peer assessment using criteria based on the Common European Framework. In this article, we present the results of a qualitative study, in which we analyze the opinions of students who took subjects in which this tool was used. Through semi-structured questionnaires, we seek to understand their expectations, reactions and opinions about the possibilities provided by WebCEF. We believe that such tool enables pre-service teachers to build up their autonomy and metacognitive strategies, which might help them to develop their oral production in a foreign language. Our study shows, however, it is still necessary to work the concepts of assessment, self-assessment and peer assessment, especially in teacher training courses, so that we can use these concepts as a source for (re)cognizing and (re)dimensioning oral production in a foreign language for the pre-service teachers.
\end{abstract}

Key words: foreign language learning and teaching; oral proficiency; WebCEF

\section{EL USO DEL WEBCEF PARA EVALUACIÓN DE LA PRODUCCIÓN ORAL EN LENGUA INGLESA EN LA FORMACIÓN INICIAL DE PROFESORES}

\footnotetext{
${ }^{1}$ Universidade Estadual Paulista "Júlio de Mesquita Filho" (UNESP), Faculdade de Ciências e Letras, Araraquara - SP - Brasil. Docente. Departamento de Letras Modernas. ORCID $<$ https://orcid.org/0000-00021531-8551>. E-mail: ana.salomao@unesp.br
} 


\section{Resumen}

Los estudios muestran que muchos profesores de inglés en Brasil imparten clases con su lengua materna por falta de confianza en su competencia oral en la lengua extranjera. En este artículo, discutimos la visión de alumnos de graduación en Letras sobre el uso del WebCEF, una plataforma en línea orientada a la evaluación de la producción oral en lengua extranjera. Ella ofrece la posibilidad de subir un vídeo grabado con la propia producción oral del aprendiz para que él se autoevalue o que sea evaluado por otra persona por medio de criterios basados en el Marco Europeo Común de Referencia para las Lenguas. En este artículo, presentamos los resultados de un estudio de naturaleza cualitativa, en el cual analizamos la perspectiva de alumnos que cursaron disciplinas en las cuales esa herramienta fue usada. Por medio del análisis de cuestionarios semiestructurados, buscamos comprender sus expectativas, reacciones y opiniones sobre las posibilidades de ayuda proporcionadas por el WebCEF. Creemos que herramientas como ésta posibilitan al profesor en formación construir su autonomía y estrategias metacognitivas que puedan auxiliarlo en el desarrollo de su producción oral en lengua extranjera. El estudio muestra, sin embargo, que aún es necesario trabajar el concepto de evaluación, autoevaluación y evaluación por pares, especialmente en la formación de profesores, para que podamos usarlos como fuente de (re) conocimiento y (re)dimensionamiento de la producción oral en lengua extranjera de los alumnos-profesores.

Palabras clave: enseñanza y aprendizaje de lenguas; competencia oral; WebCEF.

\section{Introdução}

A proficiência oral na língua estrangeira constitui um dos elementos essenciais para a internacionalização das universidades e o professor de línguas tem muito um papel importante nesse contexto. Como agente primordial na mediação da aprendizagem da língua estrangeira, o professor de línguas tem se perfil profissional constituído a partir de sua proficiência na língua que ensina. Segundo Consolo e Teixeira da Silva (2011), é essa proficiência que o auxilia a cumprir dois papéis essenciais na sua atuação em sala de aula: a compreensão e produção oral dos aprendizes. Entretanto, estudos como o de Teixeira da Silva (2008) mostram que uma grande quantidade de professores de inglês não tem proficiência oral na língua alvo e não se sente autoconfiante para ministrar suas aulas usando-a.

Concordamos com os autores citados que a competência linguístico-comunicativa na língua-alvo constitui um dos principais requisitos para que o professor de LE possa atuar como modelo linguístico e assim, colaborar, por meio de sua fala, no processo de aprendizagem com a geração de insumo adequado aos alunos. Entretanto, muitas vezes, alunos de graduação em Letras não adquirem a autoconfiança necessária para tal devido à falta de prática, já que muitos nunca lecionaram ou estiveram em uma situação de uso da língua para a comunicação espontânea, ou mesmo nunca participaram de uma conversação com um estrangeiro, seja nativo de um país onde se fala inglês como primeira língua ou não. Em muitos casos, também, esses alunos nunca se ouviram ou tiveram a chance de se observar ao falar a língua estrangeira. 
Existem ferramentas na internet hoje que auxiliam o aprendiz a avaliar sua produção oral em língua estrangeira, e, assim, tentar construir sua autonomia e estratégias metacognitivas que possam ajudá-lo no desenvolvimento de sua proficiência oral. Um desses instrumentos é o WebCEF (http://webcef.open.ac.uk/), uma plataforma para avaliação on-line da habilidade oral em língua estrangeira. Essa ferramenta não é restrita à língua inglesa e oferece a possibilidade de se autoavaliar ou avaliar outra pessoa. Para isso, o aluno precisa fazer o upload de um vídeo, que pode ser um monólogo ou interação com outra pessoa. ${ }^{2}$ Os critérios de avaliação são descritores de proficiência oral baseados no Quadro Europeu Comum de Referência para as Línguas $(\mathrm{CEF})^{3}$, que define alguns parâmetros esperados para os alunos em cada um dos níveis, a saber: utilizador elementar, independente e experiente.

Muitas vezes, aprendizes esperam que apenas o professor exerça a atividade de apontar o que pode ser melhorado em sua produção oral para que ele atinja níveis mais avançados de proficiência na língua estrangeira. Entretanto, é importante que os aprendizes se atentem à própria produção oral, pois é em situação de fala que é possível notar desvios cometidos, que na escrita podem ser identificados e corrigidos com mais facilidade devido ao tempo que se tem para pensar e reescrever. A proposta do WebCEF é estimular os aprendizes a refletirem sobre sua própria produção e sobre quais aspectos é necessário melhorá-la, uma vez que podem observar-se usando a língua.

Acreditamos, como Scaramucci (2000), que a partir do momento em que se é possível vivenciar e se autoperceber em uma prática comunicativa em outra língua, pode-se melhorar o desempenho de fala e, assim, desenvolver as habilidades linguísticas. Entendemos também que, para que o professor de língua estrangeira possa ter um melhor desempenho em suas habilidades linguístico-comunicativas na língua alvo, é necessário que se conheça seu nível de produção oral, o que envolve a auto-observação e percepção em relação a elementos como

\footnotetext{
${ }^{2} \mathrm{O}$ usuário precisa ser convidado por um outro usuário ou administrador e, assim, após criar uma senha, ter seu acesso liberado. Feito isso, ele poderá escolher uma tarefa (ou realizar aquela que o professor designou) e gravar um vídeo que deverá ser inserido na plataforma para avaliação (autoavaliação ou avaliação por outros usuários) por meio de escalas baseadas no Quadro Comum Europeu de Referências para Línguas. Tivemos acesso à plataforma devido a um curso que fizemos sobre ela com a professora Ana Beaven em 2013, uma das pesquisadoras responsáveis por sua criação.

${ }^{3}$ Desde o seu surgimento em 2001, publicado pelo Council of Europe (CE), O Quadro Comum Europeu de Referência para Línguas (Common European Framework of Reference for Languages - CEF) teve um grande impacto no ensino e na aprendizagem de línguas estrangeiras. Ele é resultado dos desenvolvimentos nas áreas educação e linguagem desde os anos 70 , com as mudanças nos métodos de ensino iniciados naquela época até os dias atuais. Sua função é descrever a habilidade que o aprendiz tem em termos de compreensão e produção oral e compreensão e produção escrita em seis níveis descritos como A1 e A2 (Usuários Elementares), B1 e B2 (Usuários Independentes) e C1 e C2 (Usuários Experientes). Essas escalas do CEF também auxiliam ao um melhor entendimento para o aprendiz e professores dos seus objetivos e metas durante o processo de ensino e aprendizagem. A utilidade do CEF se mostra na possibilidade de ter descritores para cada uma das faixas de proficiência, o que facilita sua compreensão para pessoas de diferentes lugares - apenas mencionar que o usuário é intermediário não nos diz muita coisa, pois o que é intermediário no Brasil pode não ser na Alemanha, por exemplo.
} 
fluência, acuidade, extensão de vocabulário e uso de elementos de coesão em sua fala na língua estrangeira.

Neste artigo, apresentamos uma investigação conduzida no contexto de um curso de graduação em Letras em uma universidade estadual no interior do estado de São Paulo, na qual buscamos verificar como os alunos que cursavam disciplinas de língua inglesa, na qual essa ferramenta foi utilizada, compreenderam o seu uso no que tange ao auxílio do desenvolvimento de sua produção oral na língua estrangeira.

\section{PROFICIÊNCIA EM LÍNGUA ESTRANGEIRA}

É bastante árdua a tarefa de tentar definir proficiência, seja ela relacionada à habilidade oral, seja ela relacionada às habilidades escritas. A definição do termo proficiência, segundo Olivier (2002), pode ser entendida como o nível que a pessoa tem de comando de uso das regras de linguagem, tais como os níveis fonológico, sintático, lexical e semântico, para um, alguns ou todos os aspectos no sistema oral ou escrito. Hulstijn (2011) define proficiência de forma semelhante como a medida que um indivíduo possui cognição linguística para atuar em uma dada situação comunicativa em uma determinada habilidade (compreensão oral ou escrita, produção oral ou escrita). Segundo o autor, cognição linguística é a combinação da representação da informação linguística e a facilidade com que ela é processada.

Para Byrnes (2014), proficiência pode ser definida em termos de fluência e leveza na produção ou até mesmo bom manejo do código de linguagem. Ainda para essa autora, ser proficiente é expandir o repertório geral e convencional, saindo do comum e explorando criativamente a língua. Nota-se aí também a importância do conhecimento e uso de vocabulário.

Segundo Teixeira da Silva (2000), até o advento do movimento comunicativo, proficiência em língua estrangeira significava o conhecimento demonstrável das regras gramaticais do idioma em questão, ou seja, significava ser capaz de analisar a língua, ter conhecimentos sobre ela e não necessariamente usar a língua em situações reais de comunicação. Para essa autora, a proficiência é determinada pelo nível cognitivo-linguístico geral do aprendiz e pelas exigências impostas pelas formas específicas de uso da língua. Assim sendo, aprendizes podem atuar razoavelmente em alguns contextos, exibindo proficiência em determinada habilidade, enquanto uma outra habilidade necessária para atuar em contextos diversos permanece limitada, o que acontece na própria língua materna. 
De acordo com Scaramucci (2000), ser proficiente está relacionado ao fato de o indivíduo em situações reais de comunicação ser capaz de atuar fazendo uso de formas que são gramaticalmente corretas e socialmente adequadas. É proficiente o indivíduo que for capaz de negociar significados envolvendo não só conhecimentos linguísticos, mas outros conhecimentos compartilhados e capacidades: conhecimentos de mundo, competências estratégicas, textuais, discursivas, culturais; não apenas regras da língua, mas também regras de uso dessa língua. Assim, a proficiência envolve não apenas conhecimento estático de língua e das normas socioculturais, mas a competência comunicativa para o uso dessa língua.

Tal visão também é convergente com a de Braga (2013), para quem o termo proficiência se refere à capacidade do indivíduo de usar os conhecimentos que possui de acordo com o contexto no qual está inserido com o propósito da comunicação. Sua visão vai ao encontro do que Scaramucci (2000) afirma em relação à não existência de uma proficiência única e absoluta, monolítica, baseada naquela do falante nativo ideal. Concordamos que não existe um modelo único de proficiência oral comum a todos os falantes, e que, na verdade, existem níveis de proficiência oral observados em distintos falantes em diferentes contextos.

Ainda, segundo Teixeira da Silva (2000), há falantes que são oralmente fluentes sem, contudo, exibirem a mesma fluência na escrita, por exemplo. Há os que são fluentes em língua oral, mas que se calam quando não possuem conhecimento prévio do assunto que esteja sendo tratado. Para a autora, definir proficiência oral não é uma tarefa fácil, sendo seu significado geralmente presumido em torno de definições pouco rigorosas do tipo "facilidade em se comunicar", "facilidade de expressão", entre outras, explicadas muitas vezes por definições de dicionários.

Almeida (2009, p. 21) distingue os termos capacidade linguístico-comunicativa e proficiência da seguinte forma:

Embora os termos proficiência e capacidade linguístico-comunicativa
possam ser compreendidos como sinônimos, podemos distingui-los por seu
enfoque. Enquanto a capacidade linguístico-comunicativa inclui tanto o
conhecimento da língua quanto a capacidade para usá-la socialmente,
proficiência parece ser o termo que melhor enfoca essa capacidade para o
uso. Talvez por esse motivo o campo de avaliação de língua segunda e
estrangeira tenha se apropriado do termo. Proficiência é o termo preferido
quando fazemos inferências sobre a capacidade linguístico-comunicativa do
falante por meio de amostras observáveis de desempenho na língua em
contextos específicos. (ALMEIDA, 2009, p. 21)

A mesma autora, citando Fortkamp (2000) e Ellis (2005), discute que é mais confiável avaliar os componentes de fluência, precisão, variedade lexical, coerência, entre outros, 
separadamente por causa da competição que ocorre entre esses componentes pela atenção do falante. A autora afirma ainda que os aprendizes conseguem melhorar nos componentes da precisão e complexidade quando têm a possibilidade de planejar o que será dito. Acreditamos, assim, que o uso do WebCEF pode vir ao encontro dessa proposição, pois o aluno tem a chance de se preparar para dizer algo, gravar e, posteriormente, examinar separadamente em sua produção oral a fluência, a acuidade gramatical, a extensão de vocabulário e o uso de elementos de coesão e coerência fazendo uso dos descritores providos na plataforma.

\section{Autoavaliação}

A aprendizagem de uma língua demanda estudo constante, mesmo após o período escolar, quando não há mais a figura do professor como mediador. Assim sendo, o desenvolvimento de maior autonomia para com o aprender se faz relevante. Uma das opções apontada pela literatura como desencadeadora de maior independência cognitiva é a utilização da autoavaliação (PUNHAGUI; SOUZA, 2012; KIM, 2014). Como afirmam Punhagui e Souza (2012), em nossa cultura escolar é o professor que ensina, é o professor que avalia, sendo o aluno um mero figurante do processo.

Braga (2013) ressalta que muitas das dificuldades que os professores encontram a respeito de avaliação deve-se ao fato que durante a sua formação esse assunto não é muito abordado, o que faz com que a avaliação seja tratada de maneira tradicional, na qual é o professor que define o que, como e quando avaliar sem incluir o aluno nesse processo avaliativo. Entendemos que o aluno deve ser participante ativo no seu processo de aprendizagem, portanto, ele precisa assumir a sua responsabilidade neste processo.

Para Nulty (2009), convidar os aprendizes para o processo de autoavaliação possibilita a eles uma compreensão maior do seu próprio aprendizado e de seus objetivos. É através da autoavaliação que os indivíduos avaliam as suas próprias ações e ajustam suas futuras ideias e comportamentos. Concordamos com o autor que a habilidade de avaliar seu próprio trabalho e desenvolvimento, ou mesmo de outro colega, é algo que não acontece rápida ou espontaneamente, mas, sim, é um processo desenvolvido ao longo do tempo. Outro ponto interessante seria que os benefícios da autoavaliação se estendem ao fato de o estudante aprender a colaborar e cooperar com o colega numa situação semelhante, além de ajudá-los a desenvolver o entendimento dos critérios usados para avaliar seu próprio trabalho.

Kim (2014) aponta que ferramentas de gravação de vídeo podem proporcionar uma fonte valiosa de informação para aprendizes perceberem e analisarem características das suas 
próprias falas para refletir sobre seu progresso na aprendizagem. Na pesquisa realizada por ela, os alunos relataram nas primeiras autoavaliações de seus vídeos que tinham falta de confiança para falar e repetiam o mesmo item de vocabulário muitas vezes, usando sentenças simples, sem o uso de estruturas mais complexas, e mal pronunciadas, o que também causava falta de clareza na mensagem. A autora relata que a habilidade oral dos alunos em língua estrangeira melhorou em relação à complexidade, vocabulário, gramática, discurso e pronúncia por meio da auto-observação. Os participantes afirmaram estar satisfeitos com o método de autoavaliação porque eles podiam checar e avaliar sua própria fala ao ouvir as gravações, o que aumentava sua motivação devido à autorreflexão durante o processo de aprendizagem.

Entendemos, como Kim (2014), que por meio do uso de ferramentas on-line de autoavaliação como o WebCF os alunos podem avaliar seu desempenho em diferentes etapas e desenvolver estratégias de automonitoramento, ou seja, usar estratégias metacognitivas para atingir seus objetivos, aumentando seu envolvimento ativo na aprendizagem. Concordamos com a autora que as tecnologias educacionais on-line apresentam opções inúmeras para uso no ensino e aprendizagem, especialmente para a língua inglesa, proporcionando oportunidades para a prática da autoavaliação. O uso de recursos que dão autonomia e aumentam o sentimento de apropriação e responsabilidade com o próprio processo de aprendizagem podem encorajar os aprendizes a organizar e buscar recursos mais adequados para seu desenvolvimento.

Existem muitas pesquisas sobre tecnologia e ensino, principalmente voltadas ao uso da escrita, como blogs, websites com exercícios e jogos, porém o diferencial da ferramenta relatada neste artigo é que ela foi planejada para a avaliação da produção oral de aprendizes de línguas estrangeiras, pois foca especificamente essa habilidade. No próximo tópico, faremos uma descrição detalhada do WebCEF e seus componentes.

\section{WebCEF}

O WebCEF foi um projeto desenvolvido durante os anos de 2006 a 2009 como uma ferramenta colaborativa para a avaliação da proficiência oral em língua estrangeira on-line por professores de diferentes universidades europeias, tanto para a autoavaliação como para avaliação por pares através de comunidades virtuais de prática. Ele foi financiado no âmbito do Programa Sócrates-Minerva da Comissão Europeia (DG Educação e Cultura), com o apoio da Agência Executiva de Educação, Audiovisual e Cultura. 
Segundo Baten et al. (2013), os objetivos do projeto WebCEF foram: 1) proporcionar uma plataforma na qual os professores de língua estrangeira (em serviço ou em formação) e os alunos pudessem se familiarizar com as escalas e níveis do Quadro Europeu Comum de Referências para Línguas (Council of Europe, 2001) e 2) manter de forma inovadora comunidades de prática de avaliação, para desenvolvimento das habilidades de avaliação e reflexão sobre como desenvolver a autonomia e melhorar a prática profissional dos professores e alunos.

Osborne (2014) explica os passos para se fazer uma avaliação na plataforma do seguinte modo: a) primeiramente, o professor (chamado na plataforma de mentor) deve criar uma tarefa (que pode ser totalmente nova ou modificada a partir de uma tarefa já existente) e designá-la a um novo grupo; b) os alunos devem fazer as gravações realizando a tarefa designada a seu grupo e 'upar' o arquivo na plataforma; c) os alunos devem publicar seus vídeos, escolhendo se preferem deixá-lo público (ou seja, todo o grupo poderá ver) ou privado; d) o aluno deve fazer a avaliação de seu desempenho (e/ou dos colegas) no vídeo de acordo com os descritores, podendo usar também a ferramenta de anotações para explicar suas escolhas.

Há três tipos de papéis dentro do ambiente: aprendiz, mentor e mentor de mentores. Os aprendizes só conseguem acessar as tarefas e fazer a avaliação dos vídeos. Os mentores podem criar grupos de alunos e elaborar tarefas. Os mentores de mentores podem inserir novos mentores na plataforma e têm controle irrestrito da mesma.

De acordo com Osborne (2014), o CEF tem mais de 30 diferentes escalas que podem ser aplicadas à produção oral, que incluem escalas globais, escalas analíticas para aspectos qualitativos da produção oral e escalas para competências específicas. Segundo o autor, não seria prático e nem talvez útil incluir todas elas na plataforma, portanto, o WebCEF conta somente com a escala de produção oral (oral production) e com a escala de produção oral para interação (spoken interaction), e em cada uma delas com os descritores para as escalas qualitativas básicas: desempenho geral (overall oral production/overall oral interaction), controle de vocabulário (range), acuidade (accuracy), fluência (fluency) e coerência (coherence). Os descritores estão disponíveis em 9 línguas (alemão, inglês, finlandês, francês, espanhol, italiano, holandês, português e polonês) e aparecem de acordo com a língua de trabalho escolhida na criação do grupo.

$\mathrm{Na}$ figura a seguir, retirada do tutorial do WebCEF, pode-se observar a interface da ferramenta, dividida pelos autores em quatro áreas para explicitar melhor seu funcionamento. 
Figura 1 - Visão geral do WebCEF

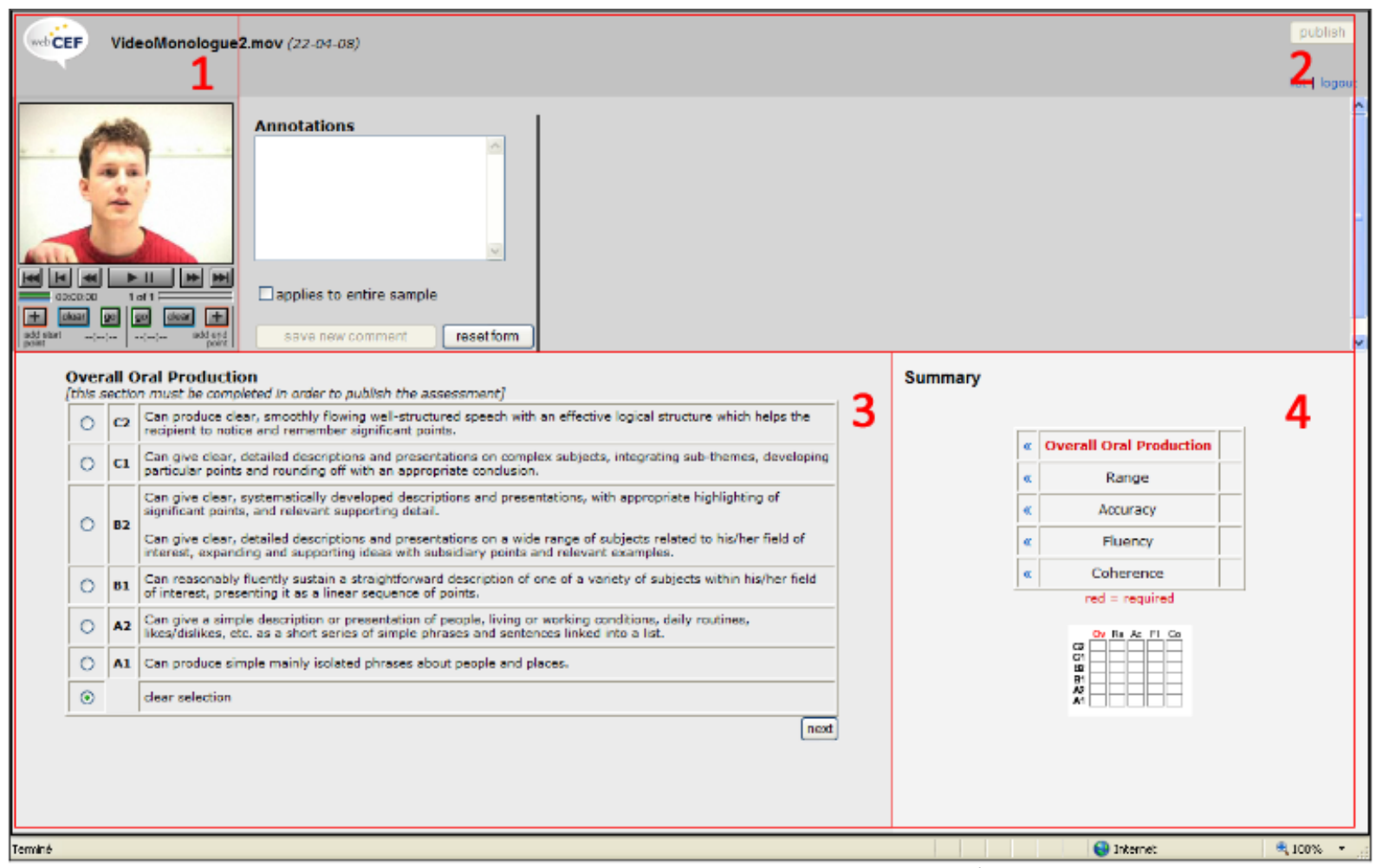

Fonte: www.webcef.open.co.uk ${ }^{4}$

Após o carregamento do vídeo, o usuário se depara com a imagem ilustrada na Figura 1, onde vê seu próprio vídeo e as escalas do CEF para avaliar o seu desempenho ou de um colega. No canto superior esquerdo (área 1), está o vídeo a ser avaliado; nesta parte é possível pausar, adiantar ou voltar o vídeo. Osborne (2014) afirma que a ferramenta de anotações (área 2) é um importante instrumento uma vez grande parte da informação mais útil em uma avaliação frequentemente não está ligada ao nível escolhido, mas ao porquê dessa escolha. A área 3 é dedicada à avaliação de acordo com a escala do CEF (A1, A2, B1, B2, C1 e C2). No canto inferior direito (área 4) está o sumário, no qual deve ser selecionado o critério a ser avaliado.

Ao final da avaliação, os resultados ficam registrados no quadro com o nível escolhido para cada um dos critérios, como se pode ver na Figura 2, a seguir.

Figura 2 - Exemplo de avaliação no WebCEF

\footnotetext{
${ }^{4}$ Para ver o tutorial completo, acessar: $<$ http://webcef.open.ac.uk/task_documents/webcef_environment.pdf $>$
} 


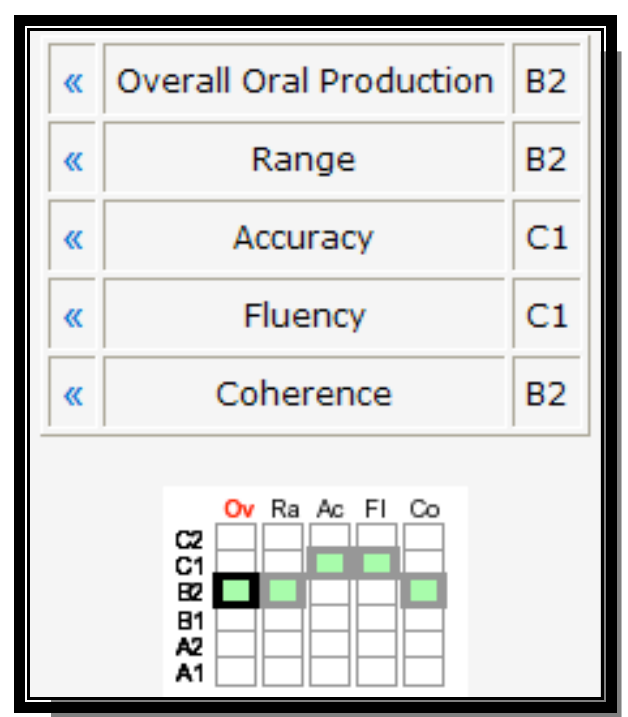

Fonte: www.webcef.open.co.uk

Na próxima seção, explicitamos a natureza do estudo, o contexto e os participantes.

\section{Metodologia}

Trata-se de uma pesquisa de caráter quantitativo e qualitativo - mixed methods research (DORNYEI, 2007), na qual aplicamos um questionário semiestruturado aos alunos de uma instituição pública no interior do estado de São Paulo do $2^{\circ}$ ano e $4^{\circ}$ anos do curso de Letras em 2014 e 2015, que cursaram disciplinas de língua inglesa nas quais o WebCEF foi usado. Nossa intenção foi compreender de que modo, na opinião dos alunos, o uso do WebCEF tem o potencial de trazer benefícios para o desenvolvimento de sua produção oral na língua estrangeira.

Como dito, os questionários foram aplicados aos alunos que cursaram disciplinas de língua inglesa nas quais a realização de atividades com o uso do WebCEF foi feita duas vezes durante cada semestre letivo. Antes do uso da ferramenta, foram dedicadas duas aulas para a apresentação e discussão do Quadro Europeu Comum (CEF) a fim de familiarizar os alunos com as escalas e os descritores. Foi realizada também, a priori, uma atividade na qual os alunos tinham de se autoavaliar segundo os descritores da Escala Global.

A partir daí o uso do webCEF se deu por meio da postagem de vídeos (monólogos ou diálogos) a partir de tasks propostas pela professora, relacionadas ao conteúdo estudado. Os alunos poderiam optar por abrir suas produções para avaliação pelos colegas também. A grande maioria preferiu deixar o vídeo em particular ("private"), de modo que apenas a professora e o próprio autor do vídeo tivessem permissão para visualizá-lo. 
Para a pesquisa foram aplicados dois questionários semiestruturados em momentos diferentes (um antes do início do uso da ferramenta e outro ao final do semestre), ambos compostos por 6 questões, que buscavam informações sobre as expectativas, reações e comentários com relação ao uso do WebCEF e opiniões sobre suas possibilidades de auxílio no desenvolvimento da produção oral dos alunos. Os questionários foram criados com a ferramenta SurveyMonkey e os alunos não eram identificados ao respondê-lo, preservando, assim, o anonimato das informações prestadas.

O quadro a seguir sintetiza o número de participantes em cada turma que respondeu aos questionários aplicados.

Quadro 1 - Total de questionários respondidos sobre uso do WebCEF

\begin{tabular}{|c|c|c|}
\hline \multirow{2}{*}{\multicolumn{2}{|c|}{$\begin{array}{l}\text { QUESTIONÁRIO } \\
\text { INICIAL SOBRE USO DO }\end{array}$}} & QUESTIONÁRIO FINAL \\
\hline & & SOBRE USO DO WEBCEF \\
\hline \multicolumn{3}{|c|}{ WEBCEF } \\
\hline \multirow{5}{*}{ 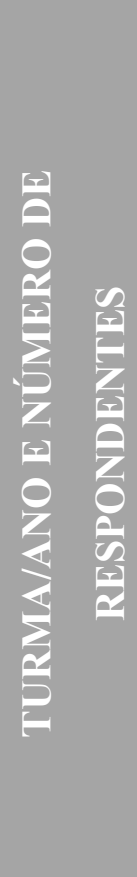 } & $\begin{array}{l}2^{\circ} \text { ano diurno/2014 } \\
\text { (12 alunos) }\end{array}$ & $\begin{array}{l}2^{\circ} \text { ano diurno } / 2014 \\
\text { (20 alunos) }\end{array}$ \\
\hline & $\begin{array}{l}4^{\circ} \text { ano diurno/2014 } \\
\text { (15 alunos) }\end{array}$ & $\begin{array}{c}4^{\circ} \text { ano diurno } / 2014 \\
\text { (24 alunos) }\end{array}$ \\
\hline & $\begin{array}{l}4^{\circ} \text { ano noturno/2014 } \\
\text { (9 alunos) }\end{array}$ & $\begin{array}{c}4^{\circ} \text { ano noturno/2014 } \\
\text { (14 alunos })\end{array}$ \\
\hline & $\begin{array}{l}4^{\circ} \text { ano diurno } / 2015 \\
\text { (14 alunos) }\end{array}$ & $\begin{array}{c}4^{\circ} \text { ano diurno } / 2015 \\
\text { (14 alunos) }\end{array}$ \\
\hline & $\begin{array}{l}4^{\circ} \text { ano noturno } / 2015 \\
\text { (14 alunos) }\end{array}$ & $\begin{array}{c}4^{\circ} \text { ano noturno/2015 } \\
\text { (12 alunos })\end{array}$ \\
\hline
\end{tabular}

Fonte: Elaboração própria

Os questionários foram respondidos em aula voluntariamente pelos alunos. Foi solicitado aos que faltaram que o fizessem em casa, entretanto, como se pode observar pelo número desigual de respondentes do questionário inicial e final na maioria das turmas, alguns não o fizeram. Analisamos todas os questionários primeiramente de forma separada a partir do levantamento de palavras-chave nas respostas dos alunos às perguntas abertas marcando as 
palavras com diferentes cores de modo a agrupar as recorrências de ordem semântica. A interpretação das opiniões dos alunos foi feita a partir dessas recorrências, chegando-se às seguintes categorias: opiniões positivas e negativas a respeito da experiência com o Webcef, comentários sobre a percepção de erros, sobre processos autoavaliativos (de autopercepção) ou relacionados à autonomia, sobre desenvolvimento de proficiência e fluência, sobre pronúncia, sobre aspectos psicológicos como ansiedade, medo de falar a LE, menções sobre a possibilidade de fazerem avaliações colaborativas ou serem avaliados por outros.

$\mathrm{O}$ caráter quantitativo da pesquisa se sobressai quando analisarmos os questionários buscando transformar as informações em dados numéricos representados em forma de porcentagens. Já o caráter qualitativo se apresenta na análise das perguntas abertas, por meio de interpretação das opiniões a partir dos relatos dos participantes. O primeiro questionário tinha perguntas em português e o segundo em inglês. Os alunos podiam optar por responder na língua que se sentissem mais confortáveis. Mantivemos os textos originais nos excertos escolhidos para ilustrar nossa discussão para não incorrer no risco de modificar o teor de suas opiniões.

A seguir apresentamos a análise e discussão dos dados coletados.

\section{Análise e discussão dos dados}

Uma das perguntas do questionário inicial buscava saber se era a primeira vez que os alunos tinham a oportunidade de ver e ou ouvir a sua própria produção oral gravada. Muito embora mais da metade (55\%) tenha afirmado que essa não era sua primeira experiência nesse sentido, quando questionados sobre como se sentiram, 60\% marcaram a alternativa "foi estranho" (para essa questão, foram dadas quatro alternativas: ótimo, bom, não tive reação, foi estranho). Poucos marcaram que não tiveram nenhuma reação (cerca de 5\%), enquanto os demais (35\%) apontaram que se sentiram bem ao ver os vídeos.

Na questão, pedia-se que explicassem a razão pela qual tinha marcado a alternativa. Notamos nos comentários que a estranheza, na verdade, teve para alguns um caráter positivo, como nos excertos mostrados a seguir:

Quadro 2: Excertos de respostas dos questionários sobre reações dos participantes ao ver seu vídeo

Percebi que a voz que eu escuto quando falo é bem diferente da que realmente é.

Foi estranho e novo. Como se fosse outra pessoa, e no entanto, era eu.

Foi estranho me ouvir pois sempre me surpreendendo com minha performance e observo que ainda tenho muito a melhorar e dou risada de minhas caras e olhares 
Foi legal me ver falando Inglês, mas ao mesmo tempo foi estranho, e achei que não falei tão espontaneamente, fiz muitas pausas.

Como nunca tinha visto/ouvido minha própria gravação em inglês, achei muito diferente de como falo em português.

Foi estranho justamente porque nunca tinha me ouvido/visto falar em inglês, mas ao mesmo tempo foi bom porque gostei da experiência.

Quando a gente fala tem a sensação de que as palavras estão saindo de uma forma mas, na verdade, estão soando de outro modo.

Escutar a própria fala é estranho. Não conhecemos a forma como a nossa voz chega às pessoas e ela sempre é diferente daquilo que escutamos no dia a dia quando falamos. É um estranhamento em relação a desconhecer algo tão próximo (a própria voz).

Fonte: Elaboração própria

Como podemos observar pelas respostas, assistir às gravações causou uma estranheza que advinha da possibilidade de se ouvir (e se olhar) a partir de outra perspectiva, de fora para dentro. Outros focaram também seus comentários em observações sobre seu desempenho na língua, como ilustrado em outros excertos a seguir.

Quadro 3: Excertos das respostas dos questionários sobre desempenho na língua alvo Porque tinha a impressão de que eu pronunciava as palavras de outro jeito.

Acho que a minha pronúncia é um tanto "forçada"

Essa foi a primeira vez que me vi falando em inglês, e isso me permitiu perceber melhor meus erros e dificuldades.

Foi melhor que a esperada, pois geralmente tenho de falar sobre pressão e isso não funciona; relaxado em casa acho que me fui razoável, dentro do nível ao qual estou adequado

It felt weird because I have never done that before so I guess it is kind of strange in the beggining, but still is a great way to notice my flaws and also my skills.

Eu não imaginava como era minha performasse (sic) em inglês, e acabou sendo pior do que eu imaginava.

Fonte: Elaboração própria

Notamos em alguns dos comentários que as reações se centraram principalmente no que tange à pronúncia e aos "erros" ou dificuldades, o que parece mostrar que a autoobservação pode despertar a percepção do aprendiz para o modo como ele faz uso a língua estrangeira. No caso do excerto em que o aluno comenta que seu desempenho foi pior do que ele/a esperava, ainda assim acreditamos que tal percepção possa aguçar seu olhar para o que precisa ser melhorado. Kim (2014) afirma que os participantes de sua pesquisa nas primeiras avaliações tinham falta de confiança e repetiam o mesmo vocabulário, usando sentenças simples sem o uso de estruturas mais complexas, mas que ao final perceberam que o uso dos vídeos os auxiliou a melhorar suas produções. Em nossa análise dos questionários, notamos também que os participantes compreenderam a experiência como uma possibilidade de 
analisar aspectos específicos de sua produção oral, como pronúncia, repetições de palavras, como podemos ver nos excertos a seguir:

Quadro 4: Excertos das respostas dos questionários sobre (auto)percepções dos participantes em relação ao uso do WebCEF

The more chances we have to see each other speaking, the more we will improve our English, because after WebCEF I realize how important is to see myself as a speaker of English and analyse critically my production.

We can point our mistakes and that is really good, like: "oh, I say 'but' too many times" or "I said 'think' like 'fink'!". I want to continue using it.

Fiquei contente em perceber que embora ainda cometa erros de pronúncia, sou capaz de me comunicar razoavelmente bem em Inglês.

It brought benefits to my oral performance as I pay more attention in how I speak and the goal I have when speaking. Now I think more about language instead of just start speaking without an intention.

Claro, ao me analisar, eu percebo quais são meus erros mais recorrentes na produção oral. Aqueles erros que não reparamos ao falar. Por isso, ao me assistir falando eu posso perceber o erro para dar atenção a ele durante a fala, conseguindo uma correção automática.

Como instrumento de autoavaliação, pois permite que o aluno se veja falando e possa notar os erros cometidos, algo que às vezes não é possível notar enquanto se fala, então ver seu próprio vídeo falando ajuda a perceber os pontos que precisam ser melhorados e também acompanhar sua melhora ao longo dos vídeos.

I could plan what I was going to say and see how my tone affects the meaning of my speech.

Mas de uma forma geral, achei que minha proficiência oral melhorou bastante desde o primeiro vídeo. Acho que estou falando com mais facilidade, conseguindo organizar e expressar minhas ideias em inglês com mais facilidade.

\section{Fonte: Elaboração própria}

Parece-nos que se observar falando a língua estrangeira trouxe à tona o uso de estratégias metacognitivas, que estão relacionadas à possibilidade de avaliar sua própria produção. Ainda, nota-se que alguns dos aprendizes apontam para a oportunidade de se preparar para falar a língua estrangeira como um fator positivo para a organização da fala, o que também pode constituir-se como uma estratégia de metacognição, segundo Purpura (2014). Cohen (2010) corrobora que a oportunidade de ensaiar o que será dito pode auxiliar a aprendizagem constituindo-se como uma estratégia de uso da língua.

Os descritores trazidos na ferramenta pareceram também oferecer critérios concretos nos quais os aprendizes poderiam se apoiar. Entendemos que ao conhecer as escalas de proficiência e analisar seu próprio desempenho, o aprendiz pode usar a escala como um guia para saber em que pontos e como pode melhorar. Nesse sentido, ele poderá observar o próximo nível da escala para estabelecer metas de desenvolvimento. Isso foi observado por alguns dos aprendizes com uma das contribuições do uso da ferramenta, como se pode ver a seguir: 
Quadro 5: Excertos das respostas dos questionários sobre (auto)avaliação no WebCEF

Before webCEF tool, I didn't know how to evaluate my own level of English, and this tool gave me specific criteria in order to define and analyze my level.

Analisar minuciosamente nossa fala, pode auxiliar bastante quando vamos estudar autonomamente, pois especifica aquilo que você precisa melhorar.

É importante avaliarmos a nós mesmos na produção oral. Através dos vídeos podemos ter uma noção de como, de fato, está a nossa produção.

Pode me ajudar a olhar para mim mesma e ter ideia do que preciso melhorar. Além disso, os níveis de proficiência são bem específicos e claro, assim dá pra saber qual nível é o seu e qual nível você quer chegar.

$\mathrm{Eu}$ creio que a ferramenta WebCEF auxiliou-me notar várias questões existentes na minha fala em inglês. Mesmo que ainda haja aspectos a serem melhorados, o WebCEF foi de grande ajuda para que eu pudesse notá-los. Além disso, permitiu-me visualizar melhor meu nível de acordo com o Quadro Europeu Comum.

\section{Fonte: Elaboração própria}

Houve um número grande de comentários sobre processos autoavaliativos (de autopercepção) ou relacionados à autonomia na aprendizagem de LE, o que nos mostra que os aprendizes compreenderam os descritores como critérios para que poderiam auxiliá-los não somente a compreender o nível atual de sua produção oral, mas como um meio de se estabelecer objetivos concretos para cada item observado (acuidade, vocabulário, fluência etc). As respostas citaram, em sua maioria, a oportunidade de "se avaliar a própria fala", do "autoconhecimento" que a atividade proporcionaria, o fato de "poder desenvolver estratégias específicas para cada deficiência".

Houve também comentários negativos a respeito do uso da ferramenta, especialmente em relação à navegabilidade do site, que é complicada e não-amigável ao usuário:

Quadro 6: Excertos das respostas dos questionários sobre dificuldades no uso do WebCEF

Tive dificuldades em postar o vídeo no site, e apenas obtive sucesso após converter o formato, apesar do original constar como compatível.

Site muito confuso, parece fórum nos anos 90. Uma simples ferramenta de upload de vídeo não deveria necessitar de instruções de navegação. Um site tem que ser fluído também, com as opções fáceis de achar.

Fonte: Elaboração própria

A plataforma tem realmente alguns problemas de navegação, já que o vídeo tem que ser postado em um lugar e depois publicado, e posteriormente deve-se clicar em outro ícone que levará à tela de avaliação. Entendemos, no entanto, que a dificuldade e cuidados dos idealizadores se deve à quantidade de recursos que ela oferece e, também, ao desejo de que os procedimentos de escolha de publicação dos vídeos de forma pública ou privada garanta 
liberdade de escolha aos usuários. Há que se considerar também que ela foi criada há cerca de dez anos e os sistemas computacionais evoluem muito rapidamente. Como não houve investimento para sua atualização, ela ainda apresenta uma interface antiga e sem as inovações da computação na atualidade.

Alguns dos participantes mencionaram ainda em seus comentários questões sobre aspectos psicológicos como ansiedade, medo de falar a LE, que foram amenizados pela possibilidade de se preparar para falar ou acentuados pela situação de ter que se filmar.

Quadro 7: Excertos das respostas dos questionários sobre aspectos psicológicos

I think I did well, sometimes it was strange to hear yourself, even in Portuguese, it is embarrassing, but I did well and I was happy with the result.

I think it is strange to see myself speaking English in a video because I could see some mistakes I make and had never noticed before. It was strange but I think it helped me a lot.

It was strange because when we are speaking without seeing it we think we are clear and the speak is perfectly, but when we are able to watch ourselves we notice mistakes we do and even how slow and fragmanted is our speaking. This experience was great and made me think more about how to speak and review some aspects of language that I confused while speaking in the recording.

Gostei da atividade pois me forçou a falar mas sem a pressão habitual, pois na verdade não pratico quase nada o speaking

Acho que sim. Porque nos primeiros vídeos gravados eu parecia me preocupar e demorar mais para fazê-los por ficar pensando palavra por palavra que diria. Agora estou conseguindo fazer isso mais rápido, mais naturalmente.

I felt very self-counscious.

I was nervous and insecure, so I don't know if my performance brought to me benefits.

I did not feel very comfortable with the whole recording process. I believe my shyness considerably affected my oral performance.

Fonte: Elaboração própria

Como se pode ver, enquanto alguns se sentiram pressionados pela atividade de modo que esse sentimento pode ter afetado seus desempenhos, outros afirmaram que, apesar da pressão, os resultados foram muitos positivos. Um deles até mesmo afirma que a atividade o deslocou da pressão habitual ("gostei da atividade pois me forçou a falar mas sem a pressão habitual"), o que provavelmente se refere a ter de falar a língua com o professor e os colegas em classe. Com isso, queremos demonstrar como a experiência foi percebida de diferentes modos pelos participantes, mas em sua maioria as percepções parecem ser mais positivas do que negativas no que tange à possiblidade de autoavaliação. Além disso, aprender a olhar para si criticamente é um processo, que se desenvolve com o tempo e prática da auto-observação. Acreditamos, assim, que ferramentas como o WebCEF podem contribuir para um melhor 
entendimento de como a autoavaliação pode contribuir para a autonomia do aprendiz, assim como fornecer mais transparência ao processo de avaliação (BATEN et al., 2013).

Em relação à possibilidade de fazer avaliações colaborativas ou ser avaliados por outros, muito embora alguns aprendizes demonstrassem concordar com os benefícios de avaliarem uns aos outros, a maioria dos alunos não deixou seus vídeos públicos (cerca de $85 \%$ ). Os excertos a seguir demonstram as diferentes percepções a respeito desse tema:

Quadro 8: Excertos das respostas dos questionários sobre avaliação colaborativa no WebCEF

Acho que funciona melhor como instrumento de avaliação colaborativa. É mais fácil notar problemas na fala do outro do que na nossa.

Se não me engano, deixei dois dos meus vídeos como públicos, apenas o último foi salvo como privado pois foi feito em dupla e minha companheira preferiu assim. Apesar de ter um pouco de vergonha é interessante ver a avaliação dos outros, porque assim como eu posso notar algo em minha fala outras pessoas também podem (inclusive coisas que eu mesma não reparei).

Sim, porque eu quero que todos vejam que não há barreiras para isso, devemos nos expor para descobrirmos nossos erros e evoluirmos.

De autoavaliação, já que por timidez muitas vezes os alunos não se expressam, então sabendo que é apenas para eles mesmos, acabam tendo a chance de ficar mais a vontade para inclusive cometer erros.

Imagino que autoavaliação. Como podemos nos ver e ouvir, notamos mais nossas repetições e problemas de pronúncia. Se todos os participantes estivessem no mesmo nível de inglês, aí sim seria mais fácil utilizar a ferramenta como colaboração, mas não é o caso atual.

Creio que o Webcef funciona melhor como instrumento de autoavaliação, pois oferece elementos para que o próprio aluno reconheça problemas em suas habilidades orais na língua estrangeira, de forma autônoma.

Autoavaliação porque muitos de nós não se sentiram a vontade para tornar os vídeos públicos, ou seja, não foi possível assistir a vídeos de muitos colegas.

Fonte: Elaboração própria

Como podemos ver, enquanto alguns concordam que a visão do outro pode auxiliá-los a notar as lacunas de sua produção, outros não se sentem confortáveis em terem seus vídeos abertos para avaliação alheia. A nosso ver, seria importante também que os colegas avaliassem a produção uns dos outros, o que poderia aguçar ainda mais suas percepções sobre a língua em uso e os elementos que compõem a produção oral por meio do uso de estratégias sociais (COHEN, 2010). Entretanto, como já dito, pouquíssimos alunos deixaram seus vídeos disponíveis para visualizações por outros colegas de classe, e os poucos que deixaram receberam poucas avaliações. Isso nos leva a pensar sobre a necessidade de trabalhar a concepção de avaliação na formação docente, a fim de desvinculá-la do conceito de julgamento. Ela é, antes de tudo, um modo de avaliar o progresso e auxiliar a busca de estratégias para contínuo desenvolvimento. 


\section{Considerações Finais}

Os processos de internacionalização do conhecimento na contemporaneidade promovem a necessidade do uso da língua inglesa, principalmente da habilidade oral, e o professor de línguas torna-se um importante agente nesse cenário. Nosso objetivo foi investigar como os alunos de graduação em Letras veem o uso da ferramenta WebCEF em relação ao seu potencial auxílio para o desenvolvimento da proficiência oral em língua estrangeira. Os resultados mostram que, de forma geral, os alunos acreditam que a ferramenta pode ajudar no desenvolvimento de sua produção oral, principalmente no que concerne às questões de pronúncia e "desenvoltura” para falar a língua.

A maioria dos participantes apontou a possibilidade de autoavaliação como seu principal benefício, principalmente por poderem usar os critérios dos descritores como fonte para compreender seu nível atual e criar metas para seu desenvolvimento. Entendemos que o conhecimento dos níveis do Quadro Europeu Comum e dos descritores de proficiência oral pode auxiliar os aprendizes a estabelecer objetivos concretos para sua aprendizagem baseando-se no conteúdo descrito próximo nível. Ao observar aquilo que já é capaz de realizar e o que é esperado para que se atinja o próximo nível, o aprendiz terá elementos para planejar suas estratégias de desenvolvimento na língua alvo. Ainda, uma vez que os descritores focam componentes específicos da produção oral (fluência, precisão, vocabulário, coesão e coerência), o aprendiz poderá observar cada um deles em seu desempenho separadamente, o que geralmente não ocorre no momento da fala devido à competição entre esses componentes.

Nesse sentido, a ferramenta WebCEF, segundo a visão dos participantes, pode auxiliar sua autoconfiança para falar a língua estrangeira, e o planejamento e a oportunidade de observar sua produção pode auxiliá-lo a desenvolver estratégias de automonitoração no momento da fala. É importante que os aprendizes compreendam o papel da autonomia na aprendizagem, e, assim, a autoavaliação por meio do uso dessa ferramenta pode ser uma forma de melhorar a autopercepção, o que fomenta o desenvolvimento de estratégias cognitivas e metacognitivas (que envolvem o uso da língua alvo, assim como o planejamento e avaliação da própria aprendizagem).

A nosso ver, a avaliação pelos colegas e posterior comparação entre todas as avaliações também seria uma contribuição importante para o aluno, especialmente no caso dos professores em formação, para que pudessem discutir questões de avaliação partindo de 
uma situação de prática, ou seja, da própria experiência de avaliar guiando-se por descritores. Como constatado no uso da ferramenta em sala de aula na pesquisa, poucos foram os que se mostraram abertos a deixar seus vídeos públicos para serem avaliados pelos colegas. Para que isso ocorra, cremos que seria necessário fazer um trabalho de compreensão de que avaliação não é julgamento, mas sim um instrumento de verificação da aprendizagem e de criação de novas estratégias de desenvolvimento.

Sugerimos que pesquisas futuras analisem o uso do WebCEF em períodos mais longos, nos quais se possa avaliar o desenvolvimento do aprendiz longitudinalmente, assim como a influência do uso dessa ferramenta em sua produção oral. Acreditamos ainda que outras pesquisas possam enfocar seu uso para o trabalho com a avaliação colaborativa na formação do professor de línguas estrangeiras.

\section{Referências}

ALMEIDA, V. B. Precisão e complexidade gramatical na avaliação de proficiência oral em inglês do formando em Letras: implicações para a validação de um teste. 2009. 269p. Tese de Doutorado. Universidade Estadual Paulista - UNESP/IBILCE, São José do Rio Preto, 2009.

BATEN, L.; BEAVEN A.; OSBORNE, J.; VAN MAELE, J. WebCEF: An online collaboration tool for assessing foreign language proficiency. In: PUMILIA-GNARINI, P.M., FAVARON, E. AND GUERRA, L. (eds). Didactic Strategies and Technologies for Education: Incorporating Advancements. Pennsylvania, IGI Global, 2013, p. 559-570.

BYRNES, H. 2014. Advanced Language Proficiency. In: GASS, S. M; MACKEY, A. The Routledge Handbook of Second Language Acquisition. New York, Routledge, p. 506-516.

BRAGA, S.R.P. A avaliação de proficiência oral no curso de Letras: a visão de professores e alunos. 2013. 167p. Dissertação de Mestrado. Universidade de Brasilia- UnB, Brasília, 2013, 167p.

COHEN, A. D. Focus on the language learner: Styles, strategies and motivation. In: SCHMITT, N. (Ed.). An introduction to Applied Linguistics. 2nd ed., London, Hodder Education. 2010, p. 161-178.

CONSOLO, D. A.. A construção de um instrumento de avaliação da proficiência oral do professor de língua estrangeira. Trabalhos em Linguística Aplicada, v. 43, n. 2. p. 264-286, 2004.

CONSOLO, D.A; TEIXEIRA DA SILVA, V.L. Desenvolvimento da proficiência oral em inglês em alunos universitários: análise de tarefas e da qualidade das interações verbais. In: SILVA, K. A.; DANIEL, F. G.; KANEKO-MARQUES, S. M.; SALOMÃ̃O, A. C. B. $A$ formação de Professores de Linguas. Campinas, Novos Olhares Pontes, 2011, p. 127-146. 
DORNYEI, Z. 2007. Research Methods in Applied Linguistics. Oxford, Oxford University Press, $336 \mathrm{p}$.

HULSTIJN, J. H. Language proficiency in native and non-native speakers: An agenda for research and suggestions for second language assessment. Language Assessment Quarterly, v.8, n.3. p. 229-249, 2011.

KIM, S. H. Developing autonomous learning for oral proficiency using digital storytelling. Language Learning \& Technology, v. 18, n. 2. p.20-35, 2014. Disponível em: http://lit.msu.edu/issues/june2014/action1.pdf. Acesso em: 28 set. 2014.

NULTY, D. D. A guide to peer and self assessment. Griffith University. 2009. Disponível em: https://www.griffith.edu.au/_data/assets/pdf_file/0016/142108/GuidePeerSelfAssessmentLong.pdf . Acesso em: 28 set. 2014.

OLIVIER, C. E. The oral proficiency of ESL teacher trainees in different domains. 2002. 79p. Tese de Mestrado. University of South Africa. Pretoria, South Africa, 2002.

PUNHAGUI, G. C; SOUZA, N. A. A autoavaliação na aprendizagem de língua estrangeira: subsídio para reconhecimento da própria aprendizagem e gestão do erro. Revista Roteiro, v. 37, n.2, p. 265-294, 2012.

PURPURA, J. E. 2014. Language Learning Strategies and Styles. In: CELCE-MURCIA, M.; BRINTON, D. M.; SNOW, M. A. Teaching English as a Second or Foreign Language. Boston, National Geographic Learning, 2014, p. 532-549.

SCARAMUCCI, M. V. R. Proficiência em LE: considerações terminológicas e conceituais. Trabalhos em Linguística Aplicada, v. 36, p.11-22, 2000.

TEIXEIRA DA SILVA, V. L. Fluência Oral: Imaginário, Construto e Realidade num Curso de Letras/LE. Campinas, SP. Tese de Doutorado. 2000. 265p. Instituto de Estudos da Linguagem. Universidade Estadual de Campinas - UNICAMP, Campinas, 2000.

TEIXEIRA DA SILVA, V. L. Em busca da fluência oral: um curso de Letras sub-judice. In: SILVA, K. A.; ALVAREZ, M. L. O. Perspectivas de investigação em Linguística Aplicada. Campinas, Pontes. 2008, p. 373-400. 